A great deal of experimental work is reviewed - much of it very elegant work. The discussion ranges as far afield as coupled pacing and the atrial contribution to closure of the mitral valve. Each idea and proposition has been tested experimentally and the authors finally integrate all the effects of sympathetic and vagal stimulation.

The sections of the book dealing with the role of the central nervous system are necessarily more philosophical and the experimental evidence less clearcut and more difficult to interpret. There is an informative section on the terminal innervation of the heart - a subject which has been neglected in the past.

This is an extremely valuable book. So much information is presented that it can be read again with advantage. The symposium took place in 1963, only a few days before the death of Carl J. Wiggers, who was to have attended it. The dedication of this important and exciting book to Dr. Wiggers seems appropriate and pleasing.

\section{Psychosomatic Disorders in Adolescents and Young Adults}

Edited by J. Hambling and Philip Hopkins. Pp. 246. Oxford and London: Pergamon Press. 1965. 60s.

This volume is the belatedly published edited Proceedings of the 1960 Conference of the Society for Psychosomatic Research. However, very few of the papers have to do with changing fashions of medicine and the delay in publication has not affected their value for the reader. The standard of the papers varies considerably and there are some poor ones. Some of them deal with specific illnesses and behaviour patterns in adolescence such as acne, appendicitis, tonsillitis, epilepsy, diabetes mellitus, tuberculosis, sexual behaviour and pregnancy. Too many of these papers are concerned only with the impact of the illness on the adolescent personality. However, the paper by Hambling on the relationship of infectious illness to stress is more penetrating. Two good papers deal with the adolescent in industry and university respectively. Others are concerned with concepts concerning the nature of adolescence and in these sections there are excellent papers by people such as Ilse Hellman, Winnicott, Dicks, Wisdom and others who succinctly and sometimes provocatively distil the essence of their years of clinical experience. The price of the book is high.

\section{NEW EDITIONS}

\section{Hormone Assays and their Clinical Applications}

J. A. LoRAINE and E. T. Bell. 2nd edition. Pp. $x v+$ 584, illustrated. Edinburgh and London: E. \& S. Livingstone. 1966. 65s.

The first edition of this book enjoys a high reputation, and this second edition lives up to its predecessor. As the preface says, a great expansion has taken place in endocrinology over the last eight years, with the development of accurate and precise methods of assay for many hormones, and this edition concentrates mainly on work published between 1958 and 1965 . The documentation of the evidence is painstaking and exhaustive.

The first chapter dealing with the principles underlying hormone assay is admirable, being at the same time detailed and understandable. No mathematical or statistical methods are included, but the reader is directed to the relevant papers. This section should be read by everyone about to undertake an investigation involving hormone assay.
The endocrine glands to which most attention is paid are the anterior pituitary gland, the adrenal cortex and the ovary. It seems a pity that the book was not made more complete by sections on the thyroid and the posterior pituitary gland.

Two extra chapters are included in this edition on the hormonal interrelationships in health and disease which will be of great interest to all who are concerned with the application of hormone assays to clinical problems. The first deals with hormonal interrelationships in gynaecological disorders and pregnancy, whilst the second deals with the effect of various synthetic compounds on pituitary and ovarian function in women.

Chemical and immunological methods are rapidly replacing biological methods, but it is a sobering thought that most of the techniques which are described in this book are outside the scope of the routine clinical laboratory and are likely to remain so for some time to come.

\section{Anatomy of the Human Body}

R. D. Lockhart, G. F. HAmilton and F. W. Fyfe.

Second Edition. Pp. ix +697 , illustrated. London:

Faber and Faber. 1966. £6 6s.

Modern anatomists, as compared to those of the classical age, have been likened to a flock of geese entering a field after the crops have been gathered in, making more noise over the few ears of corn left behind than the original reapers made over the whole harvest. The advent of a second edition of what is still a new book might tempt the cynic to ask what is new in anatomy? The answer is that new discoveries are being made in the anatomy of the central nervous system, but what is more important is a new and more imaginative approach to teaching and it is this aspect of modern trends that is attempted in the book under review.

The authors set out to write a book on systemic? anatomy, but emphasise in the introduction the place of dissection and regional anatomy in the overall study of the subject. The book has been kept to a reasonable size, and the use of illustrations and pictures is made use of to the full. The picture on the cover, reminiscent of Vesalius and Leonardo da Vinci, shows that the aim of the authors is to teach the anatomy of the living body. It is, therefore, pleasant to see surface anatomy promoted from an obscure last chapter to its place as an integral part of the study so that the student learns to see and feel the underlying anatomy of the patient.

The chapter on muscles is an attempt to correlate structure and function, which would have gladdened the heart of John Hunter because the muscles really do appear to live and move and have their being, and this section is of value not only to the student but to the practitioner and physiotherapist as well.

The chapter on the central nervous system was examined eagerly to see if those student bugbears, the brachial plexes, the petrosal nerves, and the rhinencephalon, have been lifted as by magic from the levels of blood and toil to the heights of subliminal advertising, but no; the way is still hard but the pictures make it easier. Those who lack a retentive memory often find that correlation of facts counteracts the ravages of amnesia. The academic anatomists turn to comparative anatomy, whilst the student of medicine turns to clinical application. Here, this book gains first marks, the pictures on pages 287-294 are of value to both the pre-clinical student and the clinician.

This is an imaginative book, not too big, well illumined by pictures, of value to the student and the clinician, a successful attempt at a text-book of anatomy for the modern age. 